\title{
PERANAN GURU BK DALAM MENGEMBANGKAN KARIR SISWA
}

\author{
Aep Saepuloh \\ Universitas Nahdlatul Ulama Cirebon, Jalan Sisingamangaraja No. 33, Panjunan, \\ Kecamatan Lemahwungkuk, Kota Cirebon, Jawa Barat 45111, aepsaepuloh300@gmail.com
}

\author{
Diterima 29 Juni 2020, disetujui 05 Oktober 2020, diterbitkan 20 Oktober 2020 \\ Pengutipan: Saepuloh, A (2020). Peranan Guru BK dalam Mengembangkan Karir Siswa. Gema \\ Wiralodra, Vol 11, No 2, Hal 170-179, Oktober 2020
}

\begin{abstract}
ABSTRAK
Penelitian ini dilatarbelakangi masih sangat minim persepsi terhadap proses penentuan perkembangan karir siswa. Siswa masih kurang memiliki pengetahuan mengenai dunia kerja dan informasi karir yang menunjang kematangan kompetensi kerja dan kurangnya memiliki sikap positif terhadap dunia kerja yang akan mereka hadapi di masa yang akan datang. Tujuan dari penelitian ini ialah untuk memperoleh data tentang peranan guru bimbingan dan konseling dalam mengembangkan karir kepada siswa kelas XI Multimedia di SMK Manba'ul 'Ulum Kecamatan Dukupuntang Kabupaten Cirebon. Metode yang digunakan deskiptif kuantitatif, dengan instrumen penyebaran angket. Berdasarkan hasil pembahasan terdapat hubungan peranan guru bimbingan dan konseling dengan pengembangan karir siswa kelas XI Multimedia di SMK Manba'ul Kecamatan Dukupuntang Kabupaten Cirebon. Hubungan ini ditunjukkan dengan hasil analisis nilai dari koefisien regresi diperoleh nilai sebesar 0,726 menyataakan bahwa hubungan kedua variabel ada pada rentang nilai diantara $0,60<r_{x y} \leq 0,80$, nilai korelasi tersebut dikategorikan tinggi.
\end{abstract}

Kata kunci : Peranan Guru Bimbingan dan Konseling, Pengembangan Karir

\begin{abstract}
The background of this research by students is still very minimal in view of the process of determining career development. Students lack self-understanding attitudes (abilities, interests, and personalities) related to work. Students still lack knowledge about the world of work and career information that supports the maturity of work competencies and lack of positive attitude towards the world of work they will face in the future. This problem is caused because students are required to complete the tasks given by the teacher and must be accounted for. The purpose of this study was to obtain data on the Role of Guidance and Counseling Teachers in Developing Careers for Class XI Multimedia students at SMK Manba'ul 'Ulum, Dukupuntang District, Cirebon Regency. The method used is quantitative, with a questionnaire distribution instrument. Based on the results of the discussion there is a relationship between the Role of Guidance and Counseling Teachers with the career development of Multimedia XI grade students at SMK Manba'ul, Dukupuntang District, Cirebon Regency. This relationship is shown by the results of the analysis of the value of the regression coefficient obtained a value of 0.726 states that the relationship between the two variables is in the range of values between $0.60<\mathrm{r}_{\mathrm{xy}} \leq 0.80$, the correlation value is categorized high.
\end{abstract}

Keywords: Role of Guidance and Counseling Teachers, Career Development

\section{PENDAHULUAN}

Pengembangan diri merupakan kegiatan pendidikan di luar mata pelajaran 
sebagai bagian integral dari kurikulum sekolah/madrasah (Saepuloh, 2015). Kegiatan pengembangan diri merupakan upaya pembentukan watak dan kepribadian peserta didik yang dilakukan melalui kegiatan pelayanan konseling berkenaan dengan masalah pribadi dan kehidupan sosial, kegiatan belajar, dan pengembangan karier, serta kegiatan ekstra kurikuler pendidikan (Sukiyanto, 2018). Hal itu karena pendidikan merupakan upaya sadar dan terencana institusi pembinaan anak yang dimiliki latar belakang sosial budaya dan psikologis yang berbeda dalam mencapai maksud dan tujuan pendidikan (Ariyanti, 2016). Walgito, (2005: 34) menjelaskan bahwa banyak anak-anak yang menghadapi masalah dan sekaligus menggangu tercapainya tujuan-tujuan pendidikan. Masalah yang dihadapi sangat beraneka ragam, diantaranya masalah kepribadian, sosial, agama, ekonomi dan moral serta belajar dan vokasional. Masalah-masalah tersebut sering kali terhambat kelancaran proses belajar dan mengembangan perilaku anak didik.

Hurlock (1980: 57) mendefinisikan bimbingan dan konseling merupakan salah satu komponen dari pendidikan. Mengingat bahwa bimbingan dan konseling merupakan suatu kegiatan bantuan dan tuntutan yang diberikan kepada individu pada umumnya. Hal ini sangat relevan jika dilihat dari perumusan bahwa pendidikan itu merupakan usaha ataupun upaya sadar yang bertujuan untuk mengembangkan kepribadian masyarakat menyangkut masalah perilaku atau sikap mental dan kemampuan meliputi masalah akademik dan keterampilan (Novitasari \& Nur, 2017).

Pemerintah senantiasa berupaya meningkatkan kualitas pendidikan antara lain dengan dikeluarkannya Undang-undang No 22 Tahun 1999 dan Undangundang No 25 Tahun 1999 tentang Otonomi Daerah. Yang secara langsung berpengaruh terhadap perencanaan pelaksanaan dan masalah-masalah guru. Undang-undang tersebut pada dasarnya mengatur pemberian kewenangan kepada daerah otonomi untuk mengatur dan mengurus kepentingan masyarakat menurut prakarsa sendiri berdasarkan apresiasi masyarakat setempat. Sebelumnya pembinaan pendidikan merupakan kewenangan pusat, maka dengan berlakunya Undang-undang tersebut kewenangannya berada pada pemerintah daerah kota atau kabupaten. 
Pelaksanaan pendidikan pada saat sekarang tidak terlapas dengan intervensi dari pemerintah daerah. Pelaksanaan otonomi daerah sebagai penjabaran Undang-undang No 22 Tahun 1999, pembinaan guru memerlukan perubahan dengan memberikan kewenangan yang lebih luas kepada daerah untuk semua jenjang pendidikan, pembinaan guru secara desentralistik perlu dilaksanakan sehubungan dengan semangat otonomi daerah dengan mempertimbangkan secara matang kepentingan-kepentingan dunia pendidikan secara keseluruhan, usaha menjaga integrasi nasional, serta memperhatikan keamanan psikologi guru dalam melaksanakan tugasnya dan mendapatkan jaminan kesejahteraan atas pengabdiannya. Prayitno, (2004: 381), menyatakan bahwa "Implementasi pendidikan dikaitkan dengan tugas guru yang professional harus menguasai model pembelajaran untuk dilaksanakan dan dikembangkan pada proses belajar mengajar di dalam kelas". Model pembelajaran merupakan pedoman bagi guru dan murid dalam pelaksanaan proses belajar mengajar. Monks. (1999) yang dikutif Winkel dan Hastuti, (2008: 12-13) mendefinisikan, "Model pembelajaran (model of teaching) adalah suatu perencanaan yang digunakan dalam menyusun kurikulum, mengatur materi pembelajaran atau setting lainnya".

Konteks tugas profesional guru dikaitkan pengelolaan pendidikan pada tingkat satuan pendidikan tertentu. Berdasarkan kenyataan bahwa persoalan guru di lapangan baik ditinjau dari sudut kuantitas maupun kualitasnya, merupakan masalah esensial yang menjadi pokok bahasan yang menarik perhatian dari mulai tingkat global, nasional hingga ke tingkat persekolahan, yang pemecahannya perlu dilakukan melalui pendekatan sistem. Masa-masa remaja khususnya sekolah tingkat menengah memiliki berbagai problem baik dalam belajar maupun pengembangan karir. Pada masa remaja mulai merasakan identitas diririnya, perasaan bahwa ia adalah seorang yang unik dan sedang mempersiapkan diri untuk berperan dalam masyarakat. Pada masa ini, remaja ingin mengerti dirinya sendiri dan akan menjadi apa kelak.

\section{METODE PENELITIAN}

Metode penelitian yang peneliti gunakan adalah metode survei yaitu penelitian dilakukan dengan terjun langsung ke lapangan mengambil data yang terjadi pada 
saat penelitian dilakukan dan mengadakan pengolahan data (kuantitatif). Menurut Arikunto (2006), peenelitian deskiptif kuantitatif merupakan data yang diperoleh berupa angka-angka yang selanjutnya dijabarkan ke dalam bentuk kalimat. Sedangkan Menurut Hadi (2004), tipe desain penelitian yang digunakan adalah tipe penelitian eksperimental dengan memberikan perlakuan secara alami atau apa adanya. Peneliti meneliti pengaruh variabel peranan Guru BK secara simultan dalam Mengembangkan Karir Siswa Kelas XI Multimedia SMK Manba'ul Ulum.

\section{HASIL DAN PEMBAHASAN}

Berdasarkan dengan pengujian hipotesis pertama didapatkan hubungan positif dan signifikan antara guru bimbingan dan konseling terhadap karir siswa pada Kelas Kelas XI Multimedia SMK Manba'ul Ulum. Hasil analisis tersebut dapat digunakan untuk memprediksi bahwa semakin baik guru bimbingan dan konseling maka semakin berkembang pula Karir siswa. Hal ini didukung oleh koefesien determinasi bimbingan dan konseling 29\% terhadap karir siswa $=71 \%$. Statistik Deskriptif

Statistik deskriptif atau analisa deskriptif adalah merupakan bentuk analisa data penelitian pada keseluruhan variabel untuk menjelaskan berbagai karateristik data yang mencakup nilai minimum, maksimum, rata-rata, dan standar deviasinya, frekuensi data dan histogram dari masing-masing variabel seperti yang ada pada tabel di bawah ini :

\section{Tabel 1 Hasil Statistik Deskriptif}

Descriptive Statistics

\begin{tabular}{llllllc}
\hline & & Minimum & Maximum & Mean & Std. Deviation & Variance \\
\hline Bimbingan & 22 & 79 & 117 & 90,64 & 7,774 & 60,433 \\
Konseling & & & 99 & 90,09 & 4,352 & 18,944 \\
Karir Siswa & 22 & 81 & 99 & & & \\
Valid N (listwise) & 22 & & & &
\end{tabular}

Sumber : data primer yang diolah 2019

Berdasarkan tabel diatas dideskripsikan bahwa jumlah responden $(\mathrm{N})$ ada 22. Dari 22 responden ini variabel independen bimbingan dan konseling memiliki nilai minimum 79 dan maksimum 117 dengan rata-rata total jumlah 90,64 dan 
standar deviasinya 7,774. Pada variabel dependen karir siswa minimum 81 dan maksimum 99 dengan rata-rata total jawaban 90,09 dan standar deviasinya 4,35.

Tabel 2 Frekuensi Tabel Bimbingan dan Konseling

\begin{tabular}{|c|c|c|c|c|c|}
\hline \multirow{2}{*}{$\frac{1}{\text { Valid }}$} & & Frequency & Percent & Valid Percent & Cumulative Percent \\
\hline & 9 & 1 & 4,5 & 4,5 & 4,5 \\
\hline & 0 & 1 & 4,5 & 4,5 & 9,1 \\
\hline & 3 & 1 & 4,5 & 4,5 & 13,6 \\
\hline & 4 & 1 & 4,5 & 4,5 & 18,2 \\
\hline & 5 & 1 & 4,5 & 4,5 & 22,7 \\
\hline & 7 & 3 & 13,6 & 13,6 & 36,4 \\
\hline & 8 & 1 & 4,5 & 4,5 & 40,9 \\
\hline & 0 & 1 & 4,5 & 4,5 & 45,5 \\
\hline & 1 & 2 & 9,1 & 9,1 & 54,5 \\
\hline & 2 & 3 & 13,6 & 13,6 & 68,2 \\
\hline & 3 & 3 & 13,6 & 13,6 & 81,8 \\
\hline & 4 & 1 & 4,5 & 4,5 & 86,4 \\
\hline & 7 & 1 & 4,5 & 4,5 & 90,9 \\
\hline & 9 & 1 & 4,5 & 4,5 & 95,5 \\
\hline & 17 & 1 & 4,5 & 4,5 & 100,0 \\
\hline & Total & 22 & 100,0 & 100,0 & \\
\hline
\end{tabular}

Sumber : Data Primer yang diolah 2019

Berdasarkan pada tabel diatas Bimbingan dan Konseling, Peranan Guru bimbingan dan konseling mempunyai nilai 87 terdapat 3 orang atau ( $3 / 10 \mathrm{x}$ $100 \%)=30 \%$ dan seterusnya. 
Tabel 3 Frekuensi Tabel Karir Siswa

\begin{tabular}{cccccc}
\hline & & Frequency & Percent & Valid Percent & Cumulative Percent \\
\hline Valid & 1 & 4,5 & 4,5 & 4,5 \\
3 & 1 & 4,5 & 4,5 & 9,1 \\
5 & 1 & 4,5 & 4,5 & 13,6 \\
6 & 1 & 4,5 & 4,5 & 18,2 \\
7 & 2 & 9,1 & 9,1 & 27,3 \\
8 & 1 & 4,5 & 4,5 & 31,8 \\
9 & 4 & 18,2 & 18,2 & 50,0 \\
1 & 2 & 9,1 & 9,1 & 59,1 \\
2 & 3 & 13,6 & 13,6 & 72,7 \\
3 & 1 & 4,5 & 4,5 & 77,3 \\
4 & 3 & 13,6 & 13,6 & 90,9 \\
7 & 1 & 4,5 & 4,5 & 95,5 \\
9 & 1 & 4,5 & 4,5 & 100,0 \\
Total & 22 & 100,0 & 100,0 & \\
\hline
\end{tabular}

Sumber : Data Primer yang diolah 2016

Berdasarkan tabel diatas Prestasi Belajar Siswa, yang mempunyai Nilai Prestasi 94 terdapat 3 orang atau ( $3 / 10 \times 100 \%)=30 \%$ dan seterusnya.

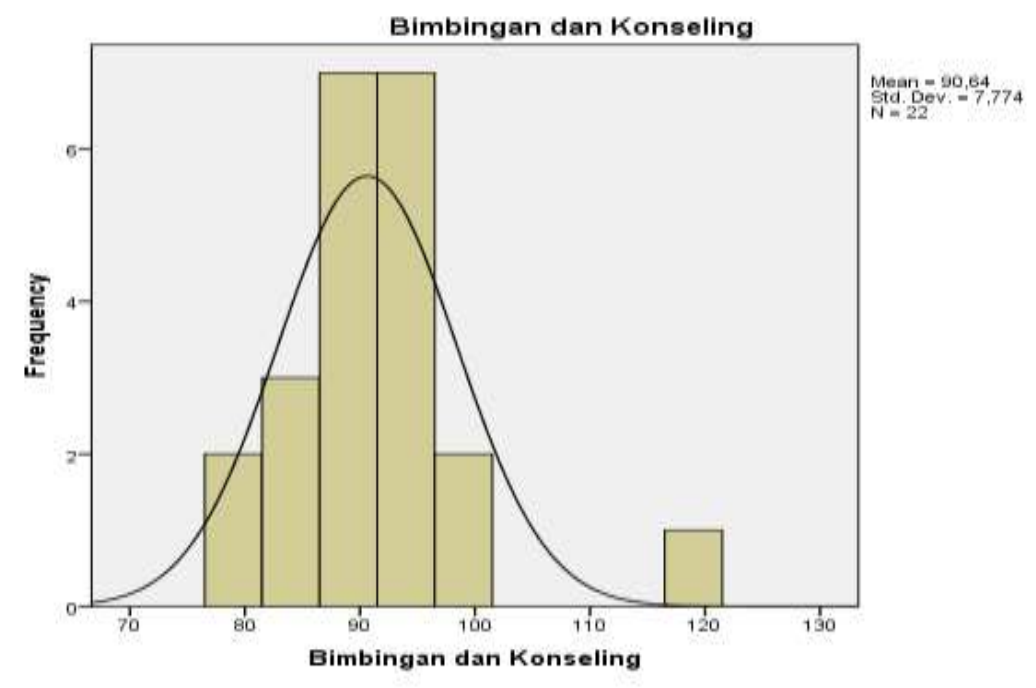

Gambar 1 Histrogram Bimbingan dan Konseling 
Berdasarkan gambar diatas batang histogram Bimbingan dan Konseling terdiri dari garis Horizontal (X) berisi nilai Bimbingan dan Konseling dan garis Vertikal (Y) berisi frekuensi Bimbingan dan Konseling.

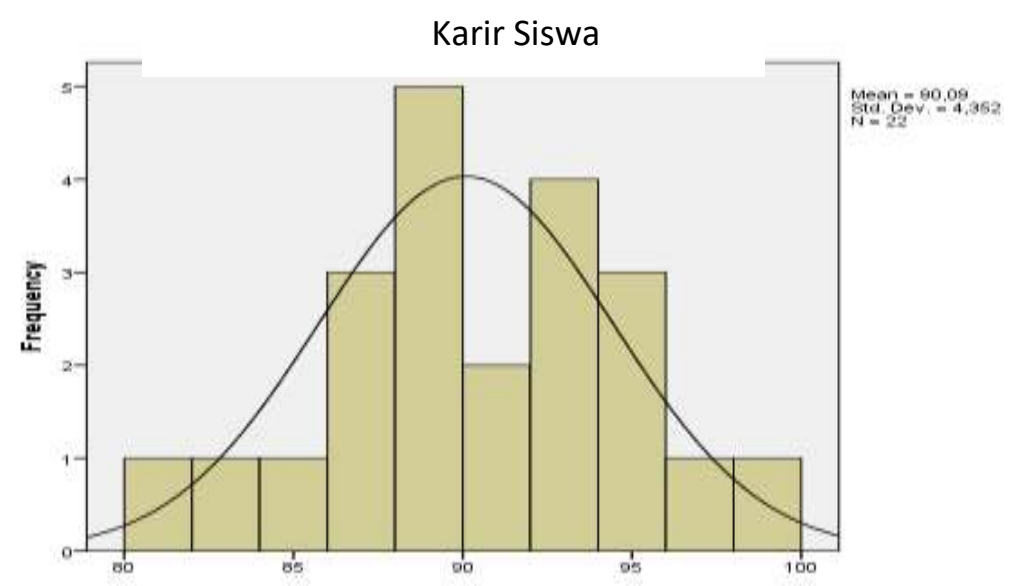

Gambar 2 Histogram Karir Siswa

Sumber : Data Primer yang diolah 2019

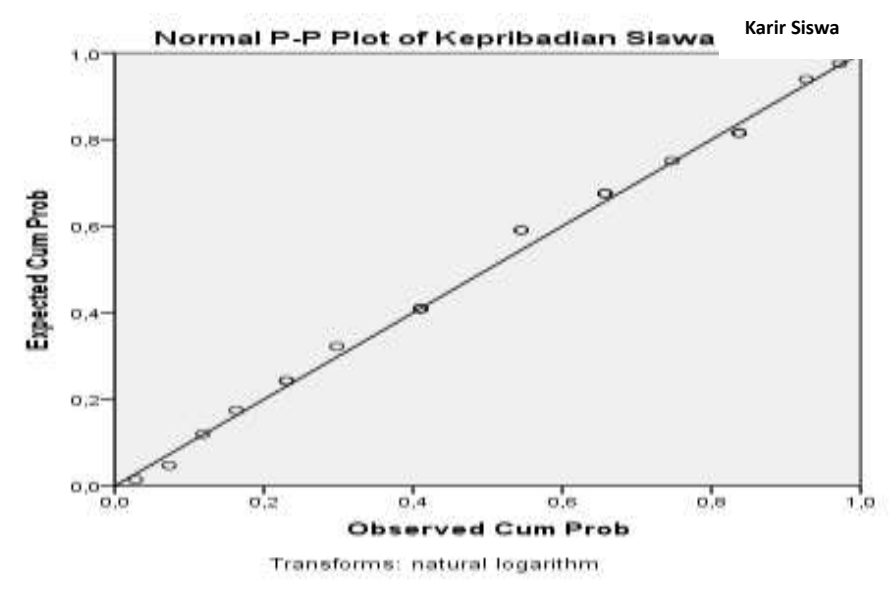

Gambar 3 Normal P-P Plot

Berdasarkan gambar diatas batang histogram terdiri dari garis Horizontal (X) berisi Karir Siswa dan garis Vertikal (Y) berisi Frekuensi Karir Siswa. Berdasarkan hasil histogram gambar 3 diatas menunjukkan bahwa semua titiktitik data tersebar disekitar garis diagonal dan searah mengikuti garis diagonal, dapat di simpulkan melalui metode probabilityPlots data Karir Siswa tersebar secara normal. 


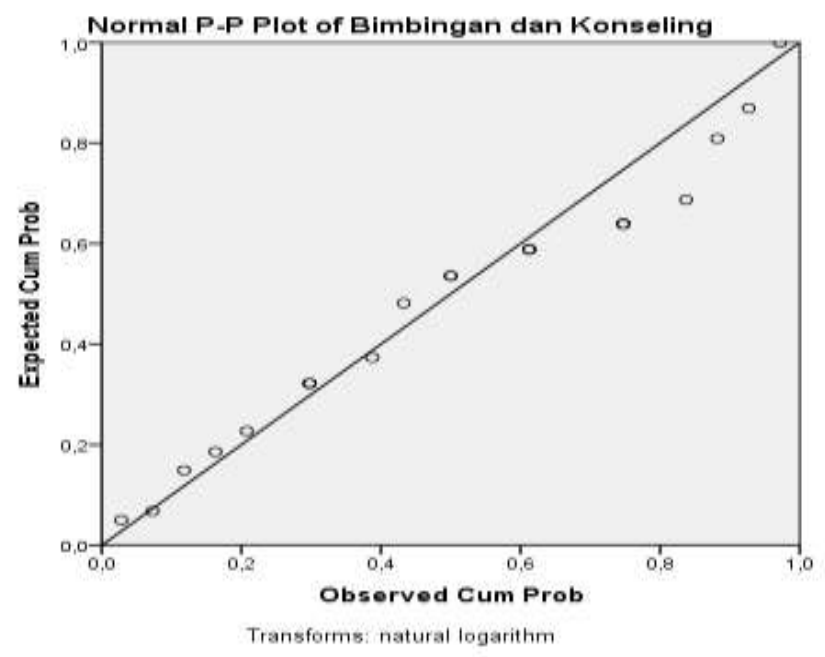

Gambar 4 Hasil Uji Normalitas Normal P-Plot

Gambar 4 di atas menunjukkan bahwa semua data variabel independen Bimbingan dan Konseling adalah normal, karena titik-titik data tersebar di sekitar garis diagonal dan mengikuti garis diagonal. Gambar 4 berikut menunjukan hasil pengujian heteroskedastisitas.

\section{KESIMPULAN}

Berdasarkan hasil pembahasan masalah mengenai peranan guru bimbingan konseling dengan pengembangan karir siswa kelas XI Multimedia di SMK Manba'ul Ulum Kecamatan Dukupuntang Kabupaten Cirebon, dapat disimpulkan bahwa hasil analisis korelasional dari data penelitian bahwa terdapat hubungan Bimbingan konseling dengan pengembangan karir siswa kelas XI Multimedia di SMK Manba'ul Ulum Kecamatan Dukupuntang Kabupaten Cirebon. Hubungan ini ditunjukan dengan hasil analisis nilai dari koeffisien regresi sebesar 0,726 menyataakan bahwa hubungan kedua variabel ada pada rentang nilai diantara 0,60 $<r_{x y} \leq 0,80$, nilai korelasi tersebut dikategorikan tinggi. Artinya bahwa semakin baik dalam pelaksanaan layanan konseling individu, maka akan semakin baik nilai dari pengembangan karir siswa.

Berdasarkan pembahasan hasil penelitian ada beberapa hal yang disarankan yaitu untuk memperoleh hasil yang maksimal dalam pengembangan karir siswa, sekolah hendaknya melengkapi berbagai sarana dan prasana yang mendukung terhadap layanan dalam pengembangan karir siswa yang disajikan 
oleh guru Bimbingan dan Konseling dan sekolah hendaknya memberikan kesempatan kepada guru Bimbingan dan Konseling untuk mengikuti berbagai pelatihan atau seminar yang berhubungan dengan kompetensi guru yang berkaitan dengan peranan guru bimbingan konseling.

\section{DAFTAR PUSTAKA}

Aep Saepuloh. 2015. Dampak Pola Pengembangan Diri Terhadap Kemandirian dan Prestasi Belajar Anak Asuh di Yayasan Manarussalam Kota Cirebon. Jurnal Gema Wiralodra, 15, 122.

Arikunto, S. 2006. Prosedur Penelitian Suatu Pendekatan Praktek (Edisi Revisi). Jakarta: Rineka Cipta.

Ariyanti, T. (2016). Pentingnya Pendidikan Anak Usia Dini Bagi Tumbuh Kembang Anak The Importance of Childhood Education for Child Development. Dinamika Jurnal Ilmiah Pendidikan Dasar, 8(1).

Elizabeth B Hurlock. 1980. Development Psychology A Life-Span Approach. New York: McGraw-Hill.

Hadi, S. 2004. Metodologi Reasearch. Yogyakarta: Andi Offset.

Irwan1 et al. 2017. Perancangan Software Bimbingan Dan Pengembangan Karir Siswa Dalam Pengambilan Keputusan Dan Konsultasi. Jurnal Teknologi Informasi dan Ilmu Komputer (JTIIK), Vol. 4, No. 4, 2017: 237-243.

Mohamad Muspawi, 2017, Menata Pengembangan Karier Sumber Daya Manusia Organisasi. Jurnal Ilmiah Universitas Batanghari Jambi 17, 114.

Monks. 1999. Psikologi Perkembangan. Yogyakarta: UGM.

Novitasari, Y., \& Nur, M. (2017). Bimbingan dan konseling belajar (akademik) dalam perspektif Islam. Indonesian Journal of Educational Counseling, 1(1), 53-78.

Nurihsan, A. J. 2003. Dasar-dasar Bimbingan dan Konseling.Bandung: Mutiara.

Prayitno, E.A. 2004. Dasar-Dasar Bimbingan dan Konseling. Jakarta : Rineka Cipta.

Rusmana, N. 2009. Bimbingan dan Konseling Kelompok di Sekolah (Metode, Teknik, dan Aplikasi). Bandung: Rizki Press.

Sukiyanto, S. (2018). Pengelolaan Layanan Pengembangan Diri Di Sekolah 
Perbatasan. Jurnal Sosialita, 10(2).

Shaleh, A. R. 2004. Psikologi Suatu Pengantar (dalam Perspektif Islam). Kencana: Jakarta.

Sukardi, D.K. 2000. Pengantar Pelaksanaan Program Bimbingan Konseling di Sekolah, (Rineka Cipta: Jakarta.

Suryana. 2011. Sikap sebagai Motivasi diri dalam bekerja. Yogyakarta: Pustaka Ilmu.

Undang-undang No 22 Tahun 1999 dan Undang-undang No 25 Tahun 1999 tentang Otonomi Daerah.

Walgito, B. 2004. Bimbingan dan Konseling di Sekolah. Yogyakarta.

Winkel \& Hastuti, S. 2008. Bimbingan dan konseling kelompok. Jakarta: Rineka Cipta. 